\title{
Performance of packed bed biofilter during transient operating conditions on removal of xylene vapour
}

\author{
V. Saravanan • M. Rajasimman • N. Rajamohan
}

Received: 5 August 2012/Revised: 27 September 2012/ Accepted: 11 January 2014 / Published online: 31 January 2014

(C) Islamic Azad University (IAU) 2014

\begin{abstract}
The performance of two laboratory-scale biofilters packed with pressmud (BF1) and sugarcane bagasse (BF2) was evaluated for gas-phase xylene removal under various operating conditions. Biofilter was inoculated with a mixed culture obtained from pharmaceutical sludge. Experiments were carried out at different flow rates $(0.03$, $0.06,0.09$ and $\left.0.12 \mathrm{~m}^{3} \mathrm{~h}^{-1}\right)$ and inlet xylene concentrations $\left(0.2,0.4,0.6\right.$ and $\left.1.2 \mathrm{~g} \mathrm{~m}^{-3}\right)$. A maximum removal efficiency of 99 and $95 \%$ were achieved at an inlet concentration of $0.2 \mathrm{~g} \mathrm{~m}^{-3}$ and gas flow rate of $0.03 \mathrm{~m}^{3} \mathrm{~h}^{-1}$ for $\mathrm{BF} 1$ and $\mathrm{BF} 2$, respectively. The dynamic behaviour of the biofilter was tested at different process conditions through vigorous short, medium and long-term shock loads. The biofilter was found to respond apace to rapid changes in loading conditions. The stability of the biomass within the reactor was apparent from the fast response of the biofilter to recuperate and handle intermittent shutdown and restart operations.
\end{abstract}

Keywords Pressmud - Sugarcane bagasse - Xylene . Shutdown · Shock loading

\section{Introduction}

In recent years, biofiltration has been applied to treat gases contaminated by low concentrations of biodegradable

V. Saravanan $(\bowtie) \cdot$ M. Rajasimman

Department of Chemical Engineering, Annamalai University,

Annamalai Nagar 608002, Tamilnadu, India

e-mail: sarav304@gmail.com

N. Rajamohan

Department of Chemical Engineering, Sohar University,

Sohar, Sultanate of Oman volatile organic compounds (VOCs). Conventional biofilters are designed and operated in a manner that limits implementation of engineering decisions that could result in improved performance during transient periods of elevated contaminant loading (i.e. shock loads). These shock loads produce the relatively uncontrolled, unsteady-state conditions commonly encountered in industrial systems. In general, methods which could improve overall biofilter performance by increasing an operator's ability to control the spatial distribution or robustness of the biofilter's microbial consortium have received only limited attention in the literature. Recently, the effects of unsteady-state loading on operating strategies have been applied to biofilters (Rene et al. 2010, 2012).

As knowledge about the hazardous effects of contaminants increases, industry is facing new regulations for contaminated air discharged from different activities. Those regulations are increasingly restrictive, and legal limits on emissions are continuously being lowered. The emission of malodorous chemicals is a public health concern, but it is also related to personal comfort. Numerous technologies are applied to meet new regulations, and of these, biofiltration has significant economic and environmental attractions (Devinny et al. 1999; Miller et al. 1994; Abumaizar et al. 1998). Biofiltration harnesses the efficiency of microorganisms to degrade contaminants to nonhazardous residues. It involves passing chemical-laden gases through a moist, porous medium containing active biomass. The gaseous contaminant is oxidized by the microbes that form a film on the bed material. The end product of these processes is usually sulphate and sulphur solid, but sulphite or polythionates may also accumulate (Paca et al. 2001; Okamoto et al. 2003; Elmrini et al. 2001; Tang et al. 1995). Biofilter performance is highly dependent on the nature of the carrier material, also called 
support or packing material or filter bed (Martin and Loehr 1996). The objective of this work is to study the biofilter behaviour under shock loading and shutdown conditions, which are frequent in industrial operation.

\section{Materials and methods}

\section{Biofiltration equipment}

In the present work, pressmud (BF1) and sugar cane bagasse (BF2) were used as packing materials. The BF1 and BF2 were obtained from the MRK sugar mill private limited, Sethiaythoppu, Tamilnadu, India. The packing materials were stored in a sealed plastic bag at room temperature to maintain the moisture content. The packing materials were sieved through $1-2-\mathrm{cm}$ screens, washed twice with distilled water, dried in an oven at $80{ }^{\circ} \mathrm{C}$ for
2 days and sterilized at 15 psi for 20 min. Both packing materials were mixed with a mineral salt solution prior to addition to the biofilter unit. Initial conditions were kept as follows: $\mathrm{pH} 7.0$ (adjusted with $\mathrm{NaOH}$ or $\mathrm{HCl}$ ), temperature $30{ }^{\circ} \mathrm{C}$ and moisture content (wet weight basis) $56.1 \%$. A nutrient solution contains $10.0 \mathrm{~g} \mathrm{~L}^{-1}$ of $\mathrm{NaNO}_{3}, 0.7 \mathrm{~g} \mathrm{~L}^{-1}$ of $\mathrm{Na}_{2} \mathrm{HPO}_{4}, 0.5 \mathrm{~g} \mathrm{~L}^{-1}$ of $\mathrm{KH}_{2} \mathrm{PO}_{4}$ and other trace elements. The biofilter was equipped with additional auxiliary units such as flow meters, manometers, nutrient recirculation peristaltic pump, compressor and nutrient storage vessel.

\section{Packed columns}

The two columns used in this study were made up of acrylic material. A detailed sketch of the complete assembled packed bed column was shown in Fig. 1. Both columns were $100 \mathrm{~cm}$ high with internal diameter of $5 \mathrm{~cm}$.

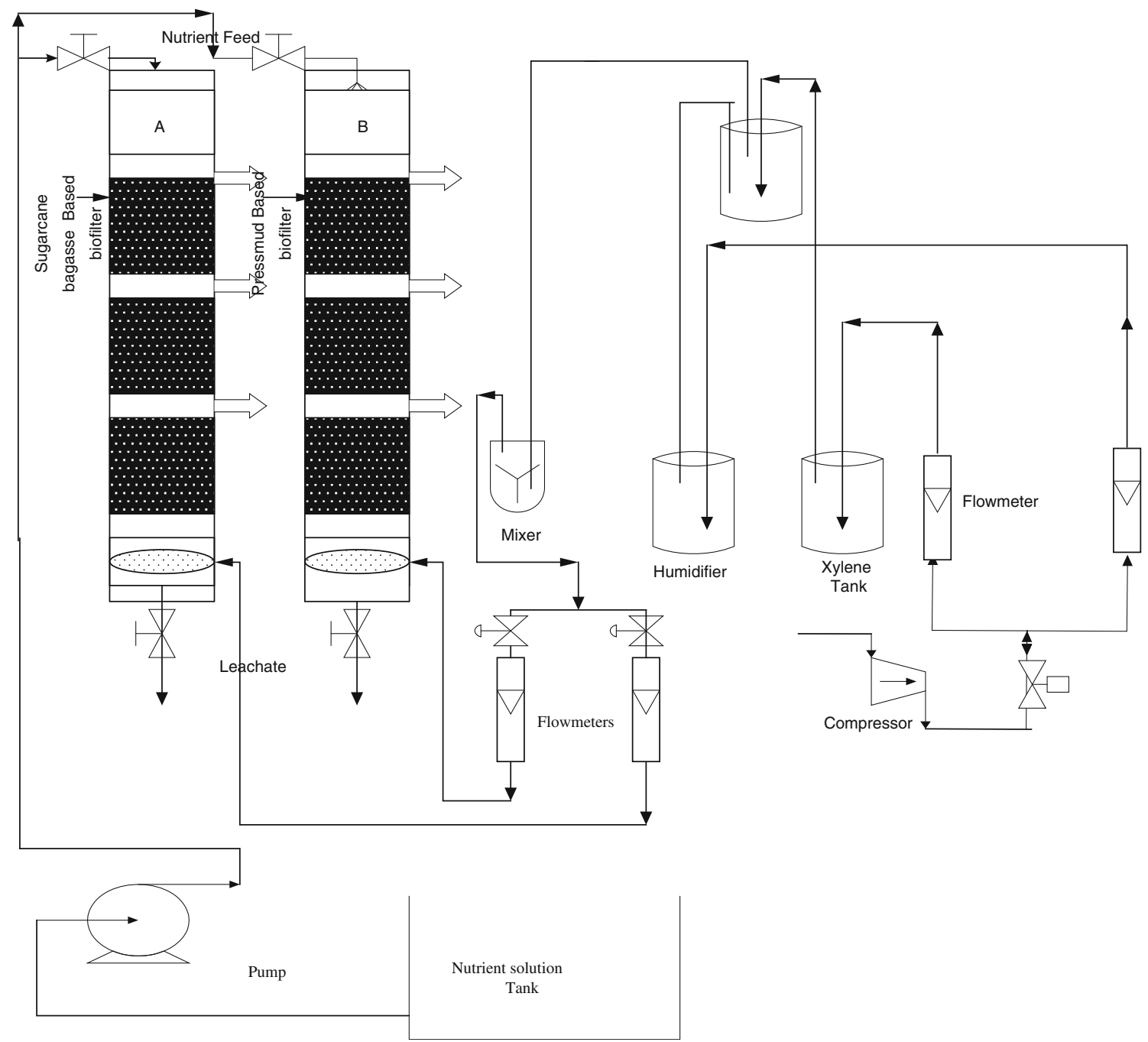

Fig. 1 Schematic diagrams for biofiltration column removing the xylene pollutant using both the packing media 
A fully packed column had three sections; a 12.5-cm-high empty space at the bottom (gas distribution section and leachate collection), followed by a $75 \mathrm{~cm}$ height of packing medium and a $12.5 \mathrm{~cm}$ height of empty space at the top (Nutrient Distribution System and outlet collection). The filter bed had three layers and each layer had a height of $25 \mathrm{~cm}$. The packing material was mixed with Berl saddles, which were packed into the filter bed. The Berl saddles were proved to be very effective to prevent bed compaction for organic packing media (Cox et al. 1993). The volume of packing media is $1.47 \mathrm{~L}$. Each column has three ports for measuring outlet concentration of xylene.

Operating conditions and experimental control

The activated sludge taken from a pharmaceutical industry plant was used as inoculum. The biofilter was operated continuously for more than 160 days. A nutrient solution was added into the filter bed from the top of the biofilter periodically to supply the nutrient for the growth of microorganisms.

The operation of biofilter was divided into four stages, and it was given in Table 1. In each stage, the biofiltration of xylene was performed at different inlet concentrations $\left(0.2-1.2 \mathrm{~g} \mathrm{~m}^{-3}\right)$ and gas flow rates $\left(0.03-0.12 \mathrm{~m}^{3} \mathrm{~h}^{-1}\right)$. The performance of reactor during transient response to shock loads and periodic shutdowns was studied. The transient behaviour of the biofilter was investigated by subjecting it to short-term shock load (STSL), mediumterm shock load (MTSL) and long-term shock load (LTSL). The STSL and MTSL were carried out by

Table 1 Operating conditions of each phase for the biofiltration

\begin{tabular}{lcll}
\hline Phase & Operating days & $\begin{array}{l}\text { Average inlet } \\
\text { concentration } \\
\left(\mathrm{g} \mathrm{m}^{-3}\right)\end{array}$ & $\begin{array}{l}\text { Flow rate } \\
\left(\mathrm{m}^{3} \mathrm{~h}^{-1}\right)\end{array}$ \\
\hline I & $0-10$ & 0.2 & 0.03 \\
& $11-20$ & & 0.06 \\
& $21-30$ & & 0.09 \\
& $31-40$ & 0.4 & 0.12 \\
II & $41-50$ & & 0.03 \\
& $51-60$ & & 0.06 \\
& $61-70$ & & 0.09 \\
& $71-80$ & 0.8 & 0.12 \\
III & $81-90$ & & 0.03 \\
& $91-100$ & & 0.06 \\
& $101-110$ & & 0.09 \\
& $111-120$ & 1.2 & 0.12 \\
VI & $121-130$ & & 0.03 \\
& $131-140$ & & 0.06 \\
& $141-150$ & & 0.09 \\
& $151-160$ & & 0.12 \\
\hline
\end{tabular}

increasing the flow rate from 0.03 to $0.12 \mathrm{~m}^{3} \mathrm{~h}^{-1}$ for a period of 12 and $17 \mathrm{~h}$, respectively. The effect of LTSLs is investigated for $17 \mathrm{~h}$ in four stages by varying the flow rate to $0.03,0.06,0.09$ and $0.12 \mathrm{~m}^{3} \mathrm{~h}^{-1}$. The transient behaviour of the biofilter was also investigated in the form of intermittent shutdown periods. The biofilter operation was stopped thrice by closing the gas stream during 6th to 10th day (5 days), 21 st to 28 th day ( 7 days) and 38th to 50 th day (12 days). Samples were collected at regular intervals of time from the inlet and outlet using an airtight syringe and analysed for residual xylene.

Analytical methods

Xylene concentrations were analysed by a gas chromatograph (Nucon5655, Amil Limited, India) with an FID detector. The carrier gas selected was nitrogen and the temperatures of column oven, injector and detector were 150,250 and $250{ }^{\circ} \mathrm{C}$, respectively. The $\mathrm{CO}_{2}$ concentrations were analysed by a gas chromatograph (Nucon5655, Amil Limited, India) with a TCD detector and a stainless steel column $(3 \mathrm{~mm} \times 2 \mathrm{~m})$. The carrier gas was nitrogen, and the temperatures of the column oven, the injector and the detector were 130,150 and $100{ }^{\circ} \mathrm{C}$, respectively.

\section{Performance evaluation}

The performance of the biofilter was evaluated by the following parameters, inlet loading rate (IL), $\mathrm{g} \mathrm{m}^{-3} \mathrm{~h}^{-1}$, removal efficiency (RE) $\%$ and elimination capacity (EC), $\mathrm{g} \mathrm{m}^{-3} \mathrm{~h}^{-1}$. Empty bed residence time (EBRT), s.

$\mathrm{RE}=\frac{C_{\mathrm{i}}-C_{\mathrm{o}}}{C_{\mathrm{i}}} \times 100 \%$

$\mathrm{IL}=\frac{F\left(C_{\mathrm{i}}\right)}{V}\left(\mathrm{~g} \mathrm{~m}^{-3} \mathrm{~h}^{-1}\right)$

$\mathrm{EC}=\frac{F\left(C_{\mathrm{i}}-C_{\mathrm{o}}\right)}{V}\left(\mathrm{~g} \mathrm{~m}^{-3} \mathrm{~h}^{-1}\right)$

$\mathrm{EBRT}=\frac{V}{F}(\mathrm{~s})$

where $V$ is the volume of the reactor in $\mathrm{m}^{3}, F$ is the flow rate of the gas in $\mathrm{m}^{-3} \mathrm{~h}^{-1}, C_{\mathrm{i}}$ is the inlet xylene concentration in $\mathrm{g} \mathrm{m}^{-3}, C_{\mathrm{o}}$ is the outlet xylene concentration in $\mathrm{g} \mathrm{m}^{-3}$.

\section{Results and discussion}

Biofiltration of air contaminated with xylene using pressmud- and sugarcane bagasse-based biofilters

The biofiltration of gas stream containing xylene was carried out for 160 days at various operating conditions in 
Fig. 2 Experimental results of continuous tests of xylene removal from air stream using pressmud as packing material for gas flow rate of a $0.03 \mathrm{~m}^{3} \mathrm{~h}^{-1}$ b $0.06 \mathrm{~m}^{3} \mathrm{~h}^{-1}$ c $0.09 \mathrm{~m}^{3} \mathrm{~h}^{-1}$ and d $0.12 \mathrm{~m}^{3} \mathrm{~h}^{-1}$

Fig. 3 Experimental results of continuous tests of xylene removal from air stream using sugarcane bagasse as packing material for gas flow rate of a $0.03 \mathrm{~m}^{3} \mathrm{~h}^{-1}$ b $0.06 \mathrm{~m}^{3} \mathrm{~h}^{-1}$ c $0.09 \mathrm{~m}^{3} \mathrm{~h}^{-1}$ and d $0.12 \mathrm{~m}^{3} \mathrm{~h}^{-1}$
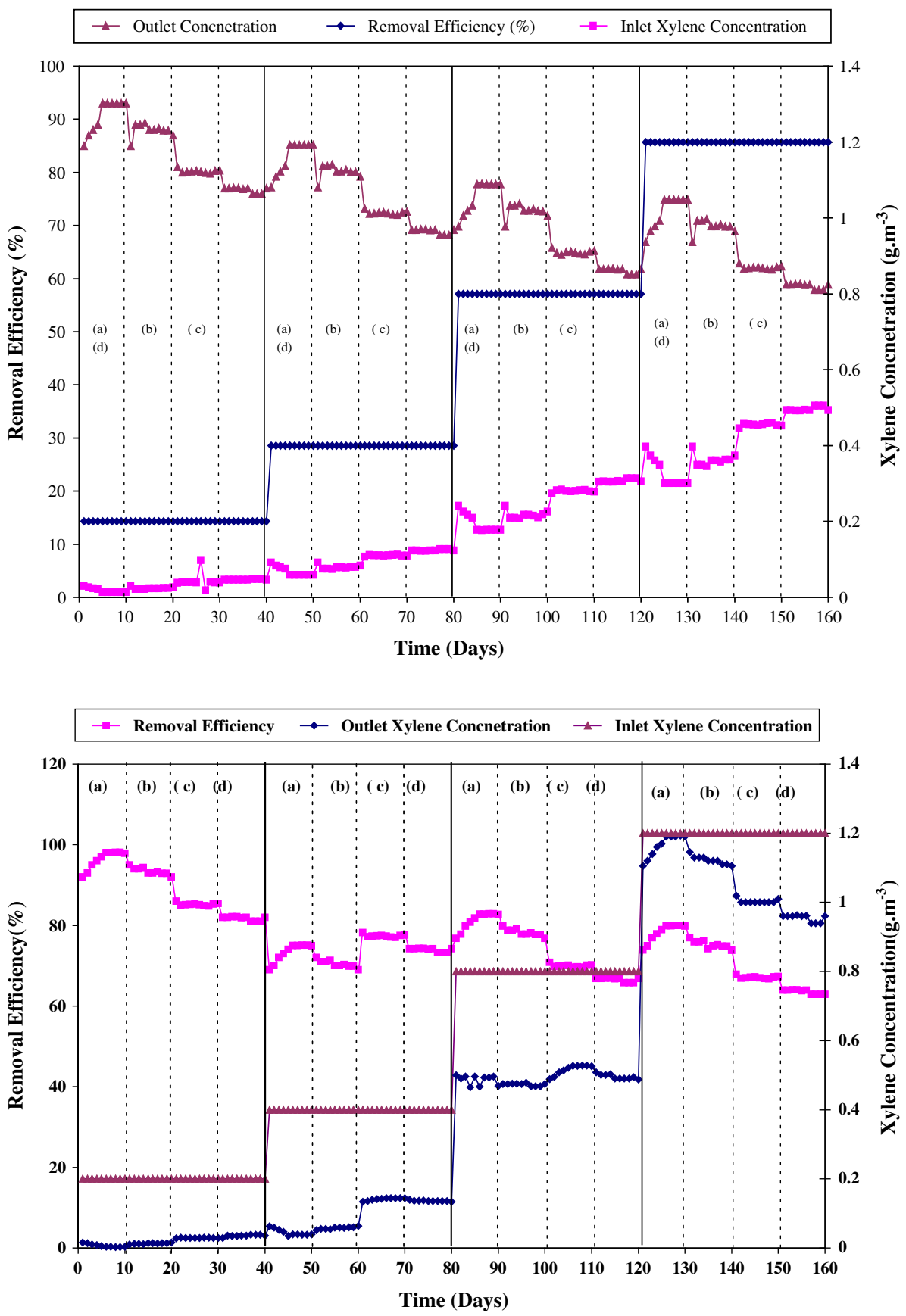

BF1 and BF2 biofilters. Each biofilter had been operated in four stages. The performance of the biofilter was studied at various loading rate by changing the flow rate and inlet xylene concentration.

The first stage of the biofiltration was carried out at an inlet xylene concentration of $0.2 \mathrm{~g} \mathrm{~m}^{-3}$ for 40 days. During the first 10 days of operation, the flow rate was maintained at $0.03 \mathrm{~m}^{3} \mathrm{~h}^{-1}$. At this condition, the corresponding loading rate and EBRT was $4.08 \mathrm{~g} \mathrm{~m}^{-3} \mathrm{~h}^{-1}$ $2.8 \mathrm{~min}$, respectively. From Figs. 2 and 3, it was observed that the RE increases gradually and reaches steady state after 8 days of operation. At steady state, a
RE of more than 99.5 and $95 \%$ was obtained in BF1 and $\mathrm{BF} 2$, respectively. The results showed that the $\mathrm{RE}$ of $\mathrm{BF} 1$ is greater than BF2. After 10 days of operation, the loading rate has been increased twice from 4.08 to $8.16 \mathrm{~g} \mathrm{~m}^{-3} \mathrm{~h}^{-1}$ by increasing the flow rate to $0.06 \mathrm{~m}^{3} \mathrm{~h}^{-1}$. The EBRT was $1.47 \mathrm{~min}$. During the initial stage, the RE of xylene decreased from 99 to $85 \%$ and 95 to $80 \%$ in BF1 and BF2, respectively, due to sudden increase in the flow rate. After 1 day of operation, the biofilters recover and reach the steady state. At this stage, the RE was found to be 95 and $91 \%$ for BF1 and $\mathrm{BF} 2$, respectively. 
Fig. 4 Effect of short-term medium shock load on the removal efficiency of the xylene vapour using pressmud-based biofilter
Fig. 5 Effect of short-term medium shock load on the removal efficiency of the xylene vapour using sugarcane bagasse-based biofilter
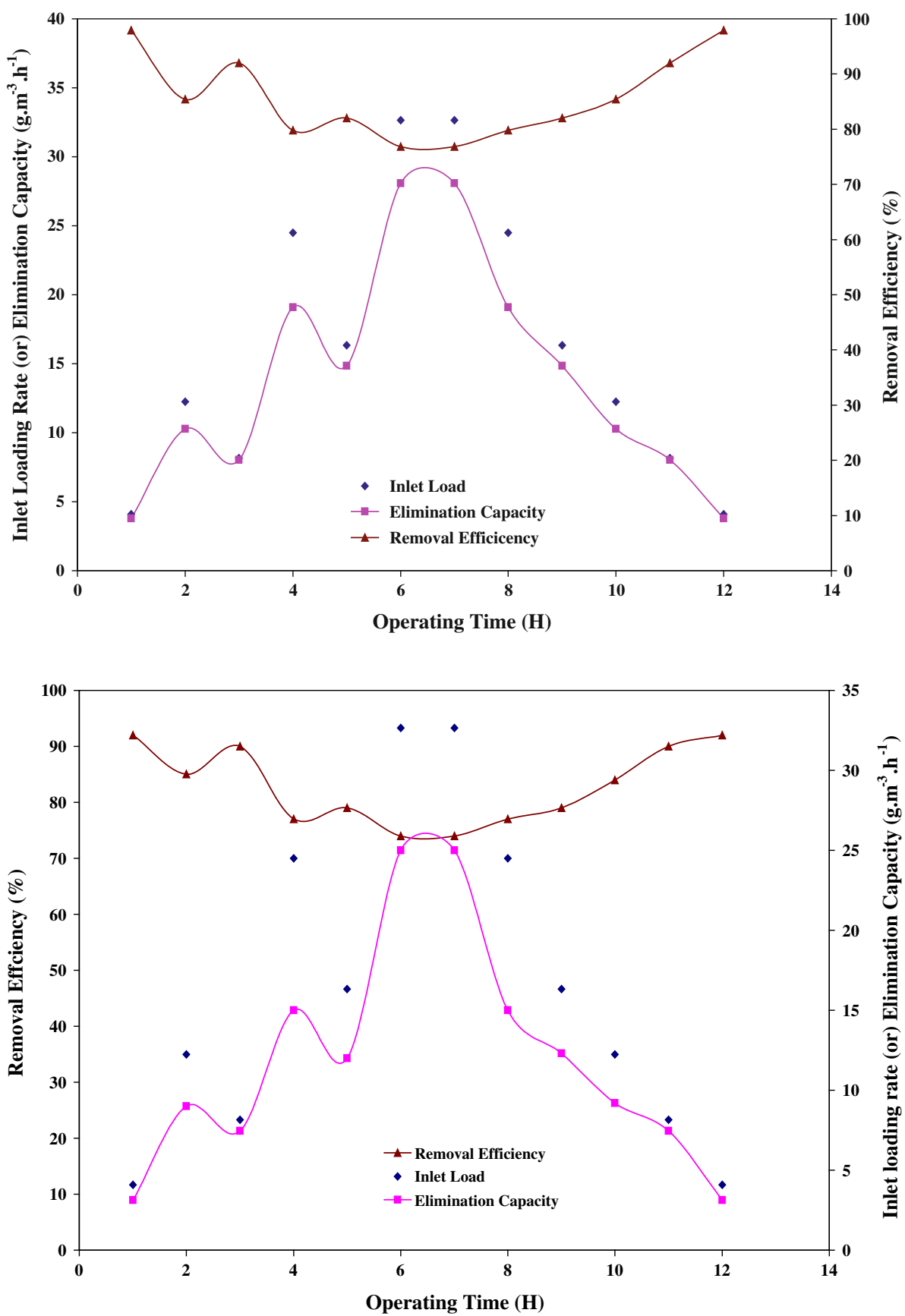

On 21st day, the loading rate was increased from 8.16 to $12.14 \mathrm{~g} \mathrm{~m}^{-3} \mathrm{~h}^{-1}$ by increasing the flow rate to $0.09 \mathrm{~m}^{3} \mathrm{~h}^{-1}$. The EBRT was $0.7 \mathrm{~min}$. With the sudden increase in the loading rate, the RE of BFI and BF2 decreased to 70 and $65 \%$, respectively. After 2 days of operation, the biofilters recover and reach a maximum RE of 90 and $88 \%$ in $\mathrm{BF} 1$ and $\mathrm{BF} 2$, respectively. After 30 days, the loading rate has been increased from 12.14 to $16.33 \mathrm{~g} \mathrm{~m}^{-3} \mathrm{~h}^{-1}$ by increasing the flow rate of gas stream to $0.12 \mathrm{~m}^{3} \mathrm{~h}^{-1}$. The EBRT was $0.45 \mathrm{~min}$. Due to this shock load, there was a fall in the RE from 90 to $61 \%$ in
$\mathrm{BF} 1$ and $55 \%$ in $\mathrm{BF} 2$, and it took 3 days to recover. It recovered gradually from this shock loading to $88 \%$ in both the biofilters.

The second, third and fourth stages of experiment were performed for different inlet concentration of $0.4,0.8$ and $1.2 \mathrm{~g} \mathrm{~m}^{-3}$, respectively. During the operation, the performance of both the biofilters were similar to the first stage. The RE of both the biofilters was found to be satisfactory and the system proved very stable during the whole experimental investigation. It shows high capacity of the cells to withstand a wide variation in pollutant 
Fig. 6 Effect of medium-term shock load on the removal efficiency of the xylene vapour using pressmud-based biofilter

Fig. 7 Effect of medium-term shock load on the removal efficiency of the xylene vapour using sugarcane bagasse-based biofilter
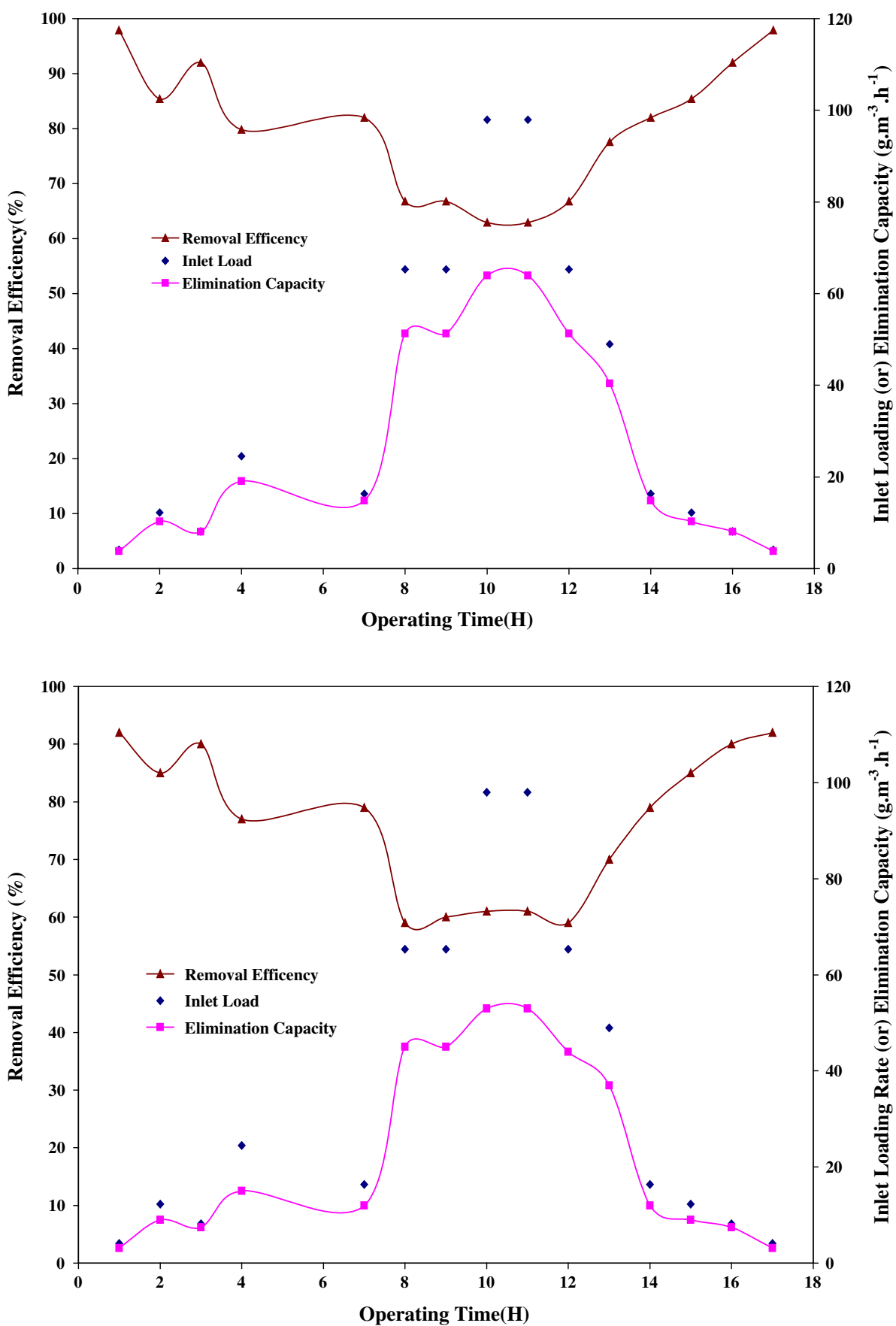

concentration as well the relative resistance of the selected sludge to toxic xylene. Steady state was assumed to be achieved when the RE under given operating conditions kept nearly constant for at least 3 days. The result obtained during the overall experimental study showed that xylene $\mathrm{RE}$ was high in BF1-based biofilter. This may be due to the property of the packing material used. The BF1 contains high water-holding capacity (Gupta et al. 2011), adequate structure for biomass development (Sene et al. 2002) and some macro and micro nutrients when compared with bagasse (Gupta et al. 2011). Similar observations were reported for benzene removal (Abumaizar et al. 1998). The maximum RE (99.5\%) obtained in this work is higher than the values reported earlier (Abumaizar et al. 1998) using mixed compost and activated carbon as packing material.

Biofilter response to shock load

The transient behaviour of the BF1 and BF2 was investigated by subjecting it to different types of shock loads, viz, STSL, MTSL and LTSL. The STSL was carried out by increasing the flow rate from 0.03 to $0.12 \mathrm{~m}^{3} \mathrm{~h}^{-1}$. During 
Fig. 8 Effect of long-term shock loads on the removal efficiency of xylene vapour using pressmud-based biofilter
Fig. 9 Effect of long-term high shock loads on the removal efficiency of xylene vapour biofilter using sugarcane bagasse-based
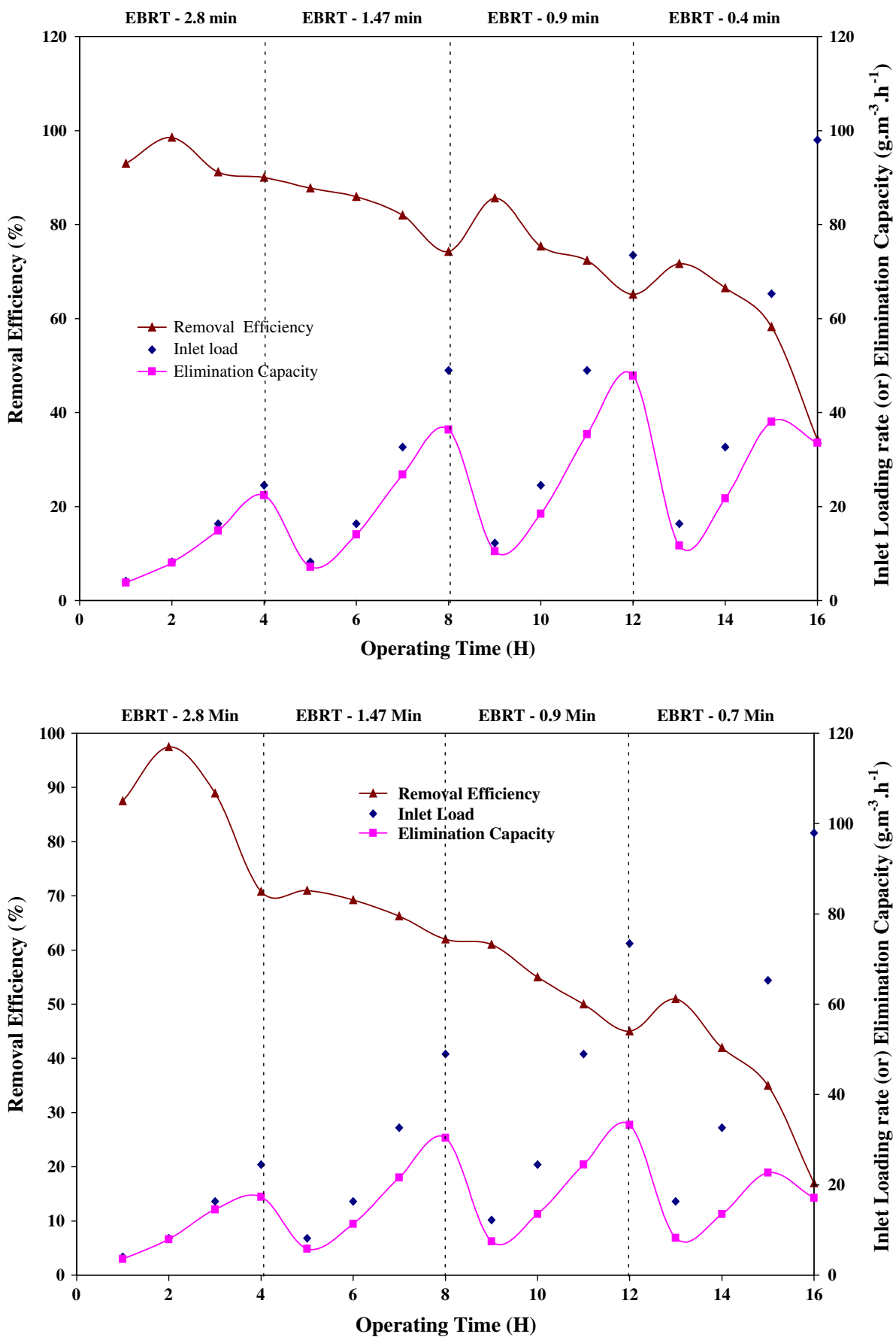

this shock load, the loading rate was increased from 4.08 to $24 \mathrm{~g} \mathrm{~m}^{-3} \mathrm{~h}^{-1}$. The results obtained were shown in Figs. 4 and 5 for BF1 and BF2, respectively. From the figures, it was observed that the biofilters were able to maintain a high performance close to $100 \% \mathrm{RE}$. The response of the biofilter was fast as seen from the immediate decrease in removal profile during STSL. The biofilter recovered almost instantaneously after both the shock loads. The results obtained in this study are inconsistent with the literature reported by Barona et al. (2004) and Jin et al. (2007).
The effect of MTSL was investigated for $17 \mathrm{~h}$ by varying the flow rate from 0.06 to $0.12 \mathrm{~m}^{3} \mathrm{~h}^{-1}$. The corresponding loading rate ranges from 12 to $97 \mathrm{~g} \mathrm{~m}^{-3} \mathrm{~h}^{-1}$. The results were depicted in Figs. 6 and 7. At loading rates lesser than $20 \mathrm{~g} \mathrm{~m}^{-3} \mathrm{~h}^{-1}$, the removal efficiencies were more than $80 \%$ during $0-7 \mathrm{~h}$. However, these values of $\mathrm{RE}$ gradually declined when the flow rate were changed in the subsequent shock loads during 7-12 h. At a loading rate of $65 \mathrm{~g} \mathrm{~m}^{-3} \mathrm{~h}^{-1}$, the RE was 66.8 and $65 \%$, for BF1 and $\mathrm{BF} 2$, respectively. When the loading rate was increased to $97 \mathrm{~g} \mathrm{~m}^{-3} \mathrm{~h}^{-1}$, the RE dropped by 6 and $1 \%$ 
Fig. 10 Response of biofilter to intermittent shutdown and restart for xylene vapour using pressmud-based biofilter

Fig. 11 Response of biofilter to intermittent shutdown and restart for xylene vapour using sugarcane bagasse-based biofilter
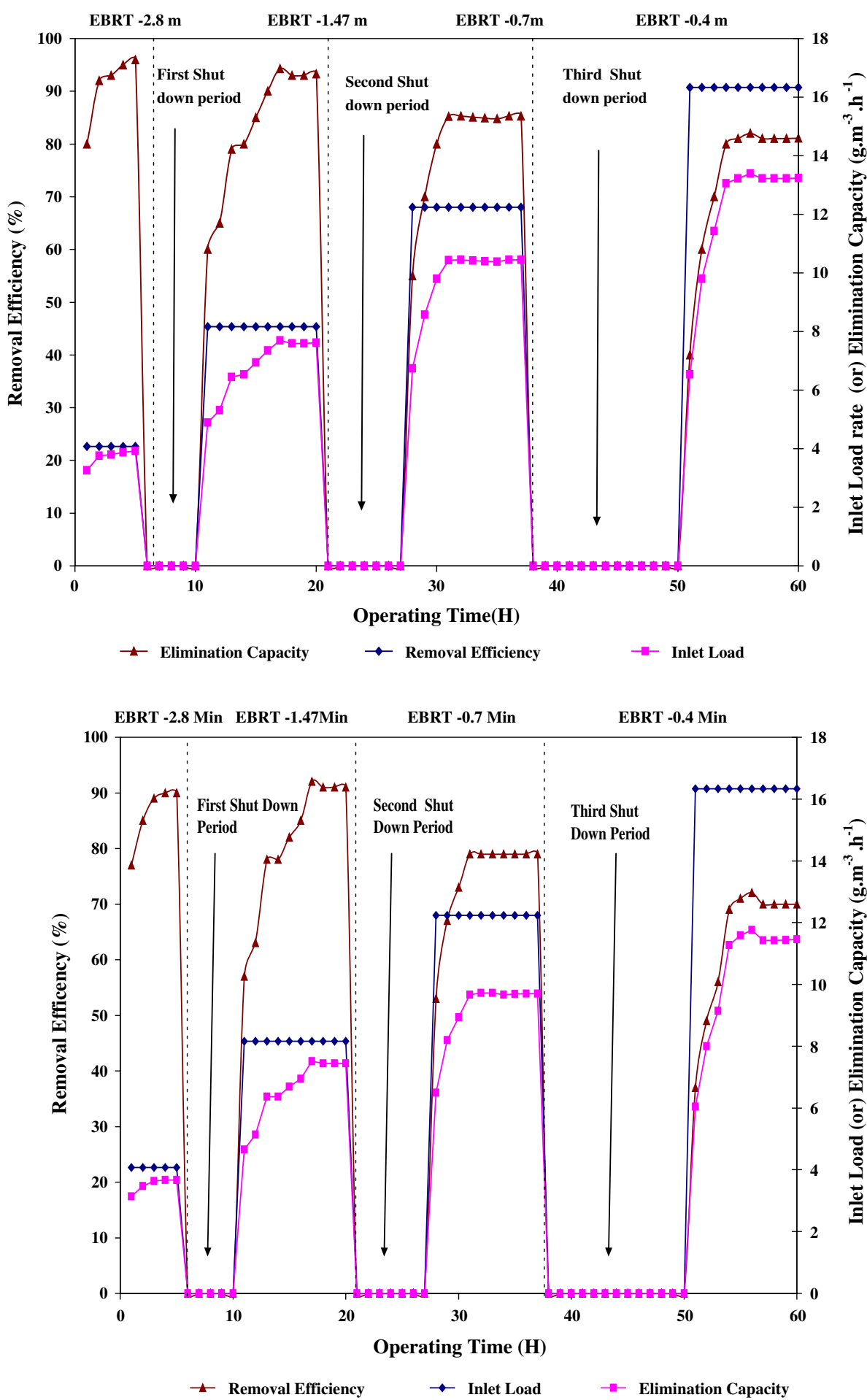

in BF1 and BF2, respectively. During 12-17 h, the loading rate was decreased to $12 \mathrm{~g} \mathrm{~m}^{-3} \mathrm{~h}^{-1}$. However, the original removal profile was almost restored when the loading rate was reduced. It is evident from the Figs. 6 and 7 for BF1 and BF2, respectively. These results clearly show the sensitivity of the biofilter to changes in loading rate due to variations in loading rate.
The effect of LTSL was investigated for $15 \mathrm{~h}$ in four stages by varying the flow rates viz. 0.03, 0.06, 0.09 and $0.12 \mathrm{~m}^{3} \mathrm{~h}^{-1}$. Corresponding loading rate varies between 4.08 and $97 \mathrm{~g} \mathrm{~m}^{-3} \mathrm{~h}^{-1}$ for these flow rates, and the results were shown in Figs. 8 and 9. At a flow rate of $0.03 \mathrm{~m}^{3} \mathrm{~h}^{-1}$, which corresponds to a loading rate lesser than $24.49 \mathrm{~g} \mathrm{~m}^{-3} \mathrm{~h}^{-1}$, the RE was higher than $90 \%$ for BF1 
and $71 \%$ for BF2 during 0-4 h. However, these values of $\mathrm{RE}$ gradually declined when both the flow rate and xylene concentration were changed in the subsequent shock loads during 5-8 h. At a loading rate of $8.16 \mathrm{~g} \mathrm{~m}^{-3} \mathrm{~h}^{-1}$, the RE was $87.75 \%$ for BF1 and $71 \%$ for BF2. When the loading rate was increased gradually to $48.98 \mathrm{~g} \mathrm{~m}^{-3} \mathrm{~h}^{-1}$, the RE dropped to $74.5 \%$ in BF1 and $60 \%$ in BF2. In the next step of $9-12 \mathrm{~h}$, the gas flow rate was increased to $0.09 \mathrm{~g} \mathrm{~m}^{-3}$ corresponding to shock loads varying between 12.24 and $73.47 \mathrm{~g} \mathrm{~m}^{-3} \mathrm{~h}^{-1}$. It was observed that the RE dropped to $65.1 \%$ in $\mathrm{BF} 1$ and $45 \%$ in BF2. In the last step, the gas flow rate was increased to $0.12 \mathrm{~m}^{3} \mathrm{~h}^{-1}$ during 13-16 h. At a loading rate of $16.33 \mathrm{~g} \mathrm{~m}^{-3} \mathrm{~h}^{-1}$, the RE was $71.65 \%$ for BF1 and $51 \%$ for BF2. But after shock loads, of $97.96 \mathrm{~g} \mathrm{~m}^{-3} \mathrm{~h}^{-1}$, the RE dropped to just $35.5 \%$ in BF1 and $20 \%$ in BF2. However, the original removal profile was almost restored when the concentration of xylene was reduced. These results clearly show the sensitivity of the biofilter to changes in loading rate due to variations in concentration and flow rate. Furthermore, it was also evident that a maximum EC of $78 \mathrm{~g} \mathrm{~m}^{-3} \mathrm{~h}^{-1}$ was achieved with $76 \%$ removal during different shock loading studies, and the critical load for $100 \%$ removal was found to be $24 \mathrm{~g} \mathrm{~m}^{-3} \mathrm{~h}^{-1}$.

\section{Biofilter response to intermittent operations}

The effect of shutdown was investigated after about 2 months of steady removal operation under non-sterile conditions. Removal pattern and RE during the three kinds of shutdown experiments were shown in Figs. 10 and 11 for $\mathrm{BF} 1$ and $\mathrm{BF} 2$, respectively. From day 1 to 5 , the experiment was carried out at an inlet concentration of $0.2 \mathrm{~g} \mathrm{~m}^{-3}$ with a gas flow rate of $0.03 \mathrm{~m}^{3} \mathrm{~h}^{-1}$. During this stage of biofiltration, a maximum RE of $96 \%$ for BF1 and $90 \%$ for BF2 was obtained. From 6th to 10th day, the biofilter was shut down. After shutdown period (11th day), $0.2 \mathrm{~g} \mathrm{~m}^{-3}$ of xylene was resupplied to the biofilter at a rate of $0.06 \mathrm{~m}^{3} \mathrm{~h}^{-1}$. Xylene RE was restored quickly and a RE of 60 and $57 \%$ was observed in $1 \mathrm{~h}$ after resupply of xylene. After 6 days of operation, the biofilters recovered to reach a maximum RE of 94 and $91 \%$ in BF1 and BF2, respectively. Again from 21st to 27th day, the biofilters were shut down. On 28th day, the gas containing xylene was passed at the rate of $0.09 \mathrm{~m}^{3} \mathrm{~h}^{-1}$ into the biofilters. A RE of 55 and $50 \%$ in $\mathrm{BF} 1$ and $\mathrm{BF} 2$, respectively, was achieved on the first day of operation. After 6 days of operation, the biofilters reach the maximum RE of 85 and $80 \%$ in BF1 and BF2, respectively. The third shutdown was performed from 39th to 50th day. After 1 day of operation in a third shutdown period, a maximum RE of 58 and $55 \%$ was obtained in $\mathrm{BF} 1$ and $\mathrm{BF} 2$, respectively. After 6 days of operation, the biofilters reach its maximum RE of more than 81 and $71 \%$ in $\mathrm{BF} 1$ and $\mathrm{BF} 2$, respectively. After the first shutdown period, xylene RE was completely recovered within 6 days, when the load was carefully controlled. However, after the second and third shutdown experiments, the RE of xylene decreases. Similar results were reported by Juneson et al. 2001.

\section{Conclusion}

This work shows promising results for the treatment of high concentrations of gas emissions containing xylene by means of two biofilters packed with BF1 and sugarcane bagasse. From the results, it was found that the complete xylene removal was possible at inlet concentration of $0.2 \mathrm{~g} \mathrm{~m}^{-3}$, irrespective of the gas residence time. Also, it was observed that the performance of biofilter depends on gas flow rate and inlet concentration. The response of the biofilter to various shock loads was found to be sensitive, as seen from the immediate decrease in RE at high loads. The restoration of RE is found to be good under low-shock loading conditions. Short-term intermittent shutdown (5 and 7 days) apparently had no effect on the biofilter performance during restart, while a 12-day shutdown period had reduced the removal by $10 \%$.

Acknowledgments The authors would like to gratefully thank the Department of chemical Engineering, Annamalai University, for providing the Environmental Engineering laboratory for carrying out this research.

\section{References}

Abumaizar RJ, Kocher W, Smith EH (1998) Biofiltration of BTEX contaminated air streams using compost-activated carbon filter media. J Hazard Mater 60:111-126

Arnold M, Reittu A, von Wright A, Martikainen PJ, Suihko M-L (1997) Bacterial degradation of styrene in waste gases using a peat filter. Appl Microbial Biotechnol 48:738-744

Barona A, Elias A, Arias R, Cano I, Gonzalez R (2004) Biofilter response to gradual and sudden variations in operating conditions. Biochem Eng J 22:25-31

Cox HHJ, Magielsen FJ, Doddema HJ, Harder W (1993) Enrichment of fungi and degradation of styrene in biofilters. Biotechnology 15:737-742

Cox HHJ, Magielsen FJ, Doddema HJ, Harder W (1996) Influence of the water content and water activity on styrene degradation by Exophiala jeanselmei in biofilters. Appl Microbiol Biotechnol 45:851-856

Cox HHJ, Moerman RE, van Baalen S, van Heiningen WNM, Doddema HJ, Harder W (1997) Performance of a styrenedegrading biofilter containing the yeast Exophiala jeanselmei. Biotechnol Bioeng 53:259-266

Devinny JS, Deshusses MA, Webster TS (1999) Biofiltration for air pollution control. Lewis Publishers, Boca Raton

Elmrini H, Kerdouss F, Jorio H, Heitz M (2001) Biofiltration of air contaminated with toluene. Environ Technol 22:927-940 
Gupta N, Tripathi S, Balomajumder C (2011) Characterization of pressmud: a sugar industry waste. Fuel 90(1):389-394

Jin Y, Guo L, Veiga MC, Kennes C (2007) Fungal biofiltration of $\alpha$ pinene: effects of temperature, relative humidity, and transient loads. Biotechnol Bioeng 96:433-443

Juneson C, Ward OP, Singh A (2001) Microbial treatment of a styrene-contaminated air stream in a biofilter with high elimination capacities. J Ind Microbiol Biotechnol 26:196-202

Leibman KC (1975) Metabolism and toxicity of styrene. Environ Health Perspect 11:115-119

Martin FJ, Loehr RC (1996) Effect of periods of non-use on biofilter performance. J Air Waste Manag Assoc 46:539-546

Miller RR, Newhook R, Poole A (1994) Styrene production, use, and human exposure. Crit Rev Toxicol 24:1-4

Okamoto K, Izawa M, Yanase H (2003) Isolation and application of a styrene degrading strain of Pseudomonas putida to biofiltration. J Biosci Bioeng 95:633-636

Paca J, Koutsky B, Maryska M, Halecky M (2001) Styrene degradation along the bed height of perlite biofilter. J Chem Technol Biotechnol 76:873-878
Rene ER, Murthy DVS, Swaminathan T (2010) Effect of flow rate, concentration and transient-state operations on the performance of a biofilter treating xylene vapors. Water Air Soil Pollut 211(1-4):79-93

Rene ER, Veiga MC, Mohammad BT, Kennes C (2012) Biodegradation of BTEX in a fungal biofilter: influence of operational parameters, effect of shock-loads and substrate stratification. Bioresour Technol 116:204-213

Sene L, Converti A, Felipe MGA, Zilli M (2002) Sugarcane bagasse as alternative packing material for biofiltration of benzene polluted gaseous streams: a preliminary study. Bioresour Technol 83(2):153-157

Tang HM, Hwang SJ, Hwang SC (1995) Dynamics of toluene degradation in biofilters. Hazard Waste Hazard Mater 12:207-219

Weigner P, Paca J, Loskot P, Koutsky B, Sobotka M (2001) The startup period of styrene degrading biofilters. Folia Microbiol $46: 211-216$ 